\title{
Social Implications of Using Online Alternative Media towards Participatory Democracy in Malaysia
}

\author{
Azlina Kamaruddin*, Rahmat Ghazali, Mariah Muda
}

University Utara Malaysia, Changlun, Malaysia

\begin{abstract}
Modern technology has resulted in rapid communication over unlimited space and it must be understood as a network of human and non-human actors bound together in seamless web. In this context, understanding the Internet should be in terms of the relationship between different actors to serve for participatory democracy. Now many types of horizontal dialogues are possible through email, chat rooms, discussion boards, usenets, real-time audio and video conferencing. Public feel disappointed since their opinions, needs, and consumptions were not wellcovered and reported through the mainstream media. Dissident voices become dominant group in order to voice out their views. This study explores the social implications of using online alternative media towards participatory democracy in Malaysia. The method employed for the collection of data is through phenomenological study where the data were collected using online asynchronous interview via emails. The researcher used thematic analysis. Nine themes emerged for the data analysis which falls under social implication. Participants need to fulfill eight criteria of being selected as interview participants. The findings showed that there is high level of awareness among the general public to participate through online alternative media. They have tendency to contribute for participatory democracy. This study suggests to other researchers who are interested in doing the same area of this study to conduct a hyperlink study; to explore other websites or other resources to enable to see the whole macro picture about the implications of online media towards participatory democracy.
\end{abstract}

Keywords: Online alternative media; Participatory democracy;

Dissident voice

\section{Introduction}

Online media is a special kind of medium, differing from earlier modalities in the variety of its applications and impact. As well as being a realm of social integration, it has important steering functions in both material production and administrative practices which should not be neglected in examining its role as a medium. The existence of online alternative media, concurrently, opens up more space for the public voice. It is an arena of citizen activity [1].

The Malaysia Prime Minister, Datuk Seri Najib Tun Razak affirmed that the online media apparatus has been used by many nations to galvanise the masses to march against the establishment, but stressed that his government recognised that practising an open digital democracy is the way forward for Malaysia. He agrees that many Western governments, which often promote freedom of expression and information, were now "forced" to review their positions. "Some of their politicians are even calling a gag on the Internet, or at least some form of government controls and regulates, in the name of national security." But Najib said, the Malaysian government would stand by its pledge to keep the Internet free from censorship [2].

\section{Background of the study}

Public needs a high level of engagement to the daily news that invites discussions and debates. Hence, the utilization of online alternative media has the potential to contribute democratic participation. In addition, the online media represents a revolutionary change in space-time relations. In seeming to extinguish space with time, cybertechnology allows communication through the online media to appear instantaneously upon demands at multiple points in an ever-shifting network of connectivity.

This study focuses on the social implications of using online alternative media towards participatory democracy. The Internet- based media is emerging as potentially critical new voice in journalism in Malaysia [3]. In regards to the above matter, the public finds and utilizes online alternative media as an answer to their unattained voices and discontentment particularly on democratic or political issues. They feel comfortable to voice out their participation in democracy and political issues and such stance has been significantly privileged when the online media offers more freedom compared to the traditional mainstream media.

\section{Statement of the problem}

With the involvement of the Internet and greater utilization of online alternative media by the opposition parties; which initially get less coverage from the mainstream mass media, this condition actually inculcates the notion of participatory democracy indirectly. The characteristics of some online alternative media, such as Malaysiakini, Malaysia Today, and the Malaysian Insider, which are interactive in nature, have actually given some space and platform to the readers and general public to express their ideas, dissatisfactions, or comments to the government or the ruling party.

As a result, the public attempts to play its role in the state of democratic landscape. Participation by the public to the national agenda setting depends on its representative to the Parliament and State Legislative Council specifically those who are voted during the election. At the same time, some do feel disappointed since their opinions, needs, and consumptions were not well-covered and reported through

*Corresponding author: Azlina Kamaruddin, Universiti Utara Malaysia, Changlun, Malaysia, Tel: +60 4-928 4000; E-mail: Iyna@uum.edu.my

Received April 26, 2015; Accepted May 25, 2015; Published June 02, 2015

Citation: Kamaruddin A, Ghazali R, Muda M (2015) Social Implications of Using Online Alternative Media towards Participatory Democracy in Malaysia. Arts Social Sci J 6: 101. doi:10.4172/2151-6200.1000101

Copyright: (c) 2015 Kamaruddin A, et al. This is an open-access article distributed under the terms of the Creative Commons Attribution License, which permits unrestricted use, distribution, and reproduction in any medium, provided the original author and source are credited. 
the mainstream medium of communication [4]. In accord to that, the public begins to explore the new medium that could provide space for them to express their own dissatisfactions, opinions, needs and wants. Participation is an on-going process. A community is a dynamic body that constantly responds to the new social and environmental conditions and often changes in the process. As such, the needs and desires of a community are also continually changing.

\section{Review of past research}

The new political landscape appears because of social change in urbanization, education, information accessing and technology [5]. The study about the importance of online research in social processes and Internet effects on political had been done after the 2008 general election in Malaysia. The expectation of the Internet usage is more to political strategy for distributed information and news [6]. The analysis identified social mechanism that determines the effects of blogs as an alternative source of information. Blogs as online alternative media has a potential for developing interpersonal relationships and their function as mobilization tools are discussed using qualitative method [6]. The general public needs to be persuaded that democracy does not mean politics spilling over into disorder in the streets but more towards applying consensus reinforcing spiral views.

The reinforcing spirals perspective highlights the need for longitudinal modeling of mutually influencing media selection and effects processes; study of the impact of such processes in youth and adolescent identity development; and analysis of social and psychological factors that control or eventually extinguish the influence of such spirals.

This perspective may also, more speculatively, be extended to address the maintenance of social identity for political, religious, and lifestyle groups. The relevance of a reinforcing spirals model to theories including spiral of silence, agenda-setting, framing, cultivation, selective attention, and uses and gratifications is also discussed.

Debates on electronic democracy provide biases in the literature because the implication is massively focused on the technology and highly Americano-centric. However, it is reasonable to argue that the literature continues to exhibit a narrow empirical focus, as long as it concerned principally with the developments in the established democracies. In Mexico, the Internet represented potential threat to the way in which it traditionally garnered votes.

However, the impacts of individuals' perceptions may be able to influence others instantly while reaching to borderless communities and the use of online social media may lead to threats [7]. Another research by Gong [8] underscores the importance of online research in illuminating the social processes underlying Internet effects on politics. It is an empirical study of the effect of blogs in the 2008 general election in Malaysia that demonstrates the significant positive effect of having a blog on the likelihood of winning a Parliamentary seat, independent of controls.

\section{Methodology}

This study is qualitative in nature. Qualitative research method is chosen because it is an umbrella term covering an array of interpretative techniques, which is more concerned with emergent themes and idiographic descriptions [9], where explanation of subjective meaning system and explanation by understanding are emphasized [10]. Qualitative research has a design to suggest or otherwise, it would be misleading [11]. It is believed that qualitative method is the best way to understand the latent meaning of content. In addition, qualitative inquiry accepts the multifaceted and energetic quality of the social world [12,13]. Qualitative research appreciates the pluralization of life worlds and the changing context of social life, therefore each phenomenon is considered unique in its own right.

The researchers think that the findings are best presented through openness, which is attainable if the general public were to be approached directly, under face-to-face situation. For such intention, the researchers decided to meet the concerned characters in person, in their natural complexity and entirely and in their everyday context, to unearth their opinions, experiences, views, ideas, insights and thought regarding the research problems and issues. However, according to some constraints, researchers decide to divide the interview session into two categories; face to face and asynchronous online interview.

On account of the above rationales of qualitative research, the researchers used semi-structured interviews as the key method to examine thoughts, ideas, experiences and views on the concerned issues. This is further advocated by the idea that this study purpose is to explore the meaning and nature of problems underpinning the implication of using online alternative media towards participatory democracy. The selections of participants provide a broad area of information to explain the complexity of the concerned research problems as well as the pluralisation of the life world.

This study employs the phenomenology design. Phenomenology was brainchild by Edmund Husserl, and then carried out by Heidegger, Sartre and Merleau-Ponty. The focus in this study would be on the essence or structure of an experience (phenomenon). Qualitative research draws from the philosophy of phenomenology in its stress on experience and interpretation [14]. Merriam also states:

The task of phenomenologist, then, is to depict the essence or basic structure of experience. Prior beliefs about a phenomenology of interest are temporarily put aside, or bracketed, so as not to interfere with seeing or intuiting the elements of structure of the phenomenon. When belief is temporarily suspended, consciousness itself becomes heightened and can be examined in the same way that an object of consciousness can be examined.

\section{Participants}

The participants for this study are general public. Some criteria of the public have been highlighted in order to assure the reliability and consistency of the data provided by them. Eight criteria of the public include; (1) willingness to participate in interview session; (2) accessibility to online media/news portal; (3) availability to interview; (4) ability to transmit information freely and accurately; (5) regardless of political ideology; (6) regardless of academic qualification; (7) regardless of gender; and (8) regardless of ethnicity. The researchers used convenience sampling to guide the idea which has significance for the emerging theory.

Convenience sampling, which is a non-probability design, not generalized at all, sometimes is used to obtain immediate information to get a feel related to the phenomenon or variable of interest. Briefly, convenience sampling involves collecting information from members of the population who are convenient to provide information $[15,16]$. In this context, those who are willing to become participants by fulfilling the basic requirements would be chosen as participants. As for qualitative content analysis, sampling is for those who are involved 


\begin{tabular}{|c|c|c|c|c|}
\hline $\begin{array}{c}\text { Participant (by } \\
\text { pseudonym) }\end{array}$ & Age & Gender & Ethnicity & Education \\
\hline Participant 1 & 35 & Male & Malay & Master degree \\
\hline Participant 2 & 41 & Female & Malay & Bachelor degree \\
\hline Participant 3 & 42 & Female & Malay & Master holder \\
\hline Participant 4 & 38 & Male & Malay & Bachelor degree \\
\hline Participant 5 & 26 & Female & Malay & Master holder \\
\hline Participant 6 & 24 & Female & Malay & Bachelor degree \\
\hline Participant 7 & 23 & Female & Malay & Bachelor degree \\
\hline Participant 8 & 25 & Female & Indian & Bachelor degree \\
\hline Participant 9 & 24 & Male & Malay & Bachelor degree \\
\hline Participant 10 & 27 & Male & Malay & Bachelor degree \\
\hline Participant 11 & 33 & Female & Malay & Masters holder \\
\hline
\end{tabular}

Table 1: Demographics of the participants.

in online conversation from the selected sections found in the three news portal.

This type of sampling would be continued until the point of saturation, when no new information of relevance to the study was found in the data. In the previous literature, the researchers found that for phenomenology, the sample size is from 5 to 25 [17]; grounded theory, at least 6 [18] and all qualitative researches, 15 is the smallest acceptable sample (Table 1 ).

\section{Conducting asynchronous online interview}

It is very important to deeply understand how the study was conducted. As a result, researchers can grasp the implications of its conclusions. As the study was based on data collected through qualitative online interviews, we need to know who the participants were, why and how they were chosen. Studies using data collected through online interviews follow fundamental steps and thinking involved in any research. It is also add important dimension of the technology. When the direct interaction between researchers and participants occur through computer-mediated communications (CMCs), technology is more than a simple transactional medium.

Online semi-structured interviews can be used to obtain feedback and offers the interviewer the opportunity to explore an issues or service. It allows participants to express their opinions, concerns and feelings. When researchers are decided to conduct online interview, there are a number of preparations that need to be done in advance to establish the trust between the interviewer and the participants. The following shows the details:

Invitations: Ask people for participations individually. In the beginning, let them know what the purpose of the study is.

Subject line: Use an effective subject line for the first contact with the participants, such as Online Research Interview. This will avoid or reduce the likelihood of a request being deleted before it is read.

Self-disclosure: Introduce and provide brief information about interviewers' professional status/credentials. Tell the participants how the researchers acquired their e-mail addresses. This will help to establish trust. There is evidence that people will engage in more selfdisclosure when they first become recipients of such self-disclosure from their interviewers.

Interview request: State the request concisely and professionally, as in "May I interview you for my PhD thesis?"

Be open about the research: Suspicion can exist when online researchers contact participants. One way to establish trust that creates rapport is to be as open as possible about the purposes and processes of the research. Outline the details of the project and specify the topic of the interview and the interview procedure, including information about interviewers and participants.

Incentives: Consider providing non-traditional incentives for people who will be willing to participate in a study. Promising participants a copy of the results may help encourage individuals to participate. Researchers should also communicate to potential participants the benefits of participation, such as the opportunity to gain perspectives on, and understanding of, their own ideas and opinions and those of their peers.

Research ethics and informed consent: Emphasize the anonymity of research ethics by giving consent letter before starting the interview.

\section{Data Analysis and Interpretation}

The data analysis is based on thematic analysis. According to Broun, the benefit of using thematic analysis is flexible approach for qualitative research. Thematic analysis is a method for identifying, analyzing, reporting patterns (themes) within data. There are six phases carrying out a thematic analysis and they are: (i) familiarizing with the data; (ii) generating initial codes; (iii) searching for themes; (iv) reviewing (themes); (v) defining and naming themes; and (vi) producing report.

There are nine themes created for social implications of using the online alternative media towards participatory democracy, as shown in Table 2.

Below are some examples of analysis and discussion part according to social implication themes.

\section{Believe that misuse of using the online media can create harm}

The usage of online alternative media may lead to threats, based on the participants' perceptions. The more they raise and repeat a particular issue on the online media, more participation of other users would have been expected. Obviously, people who are not satisfied with the ideas or comments, which are against them, probably would quarrel with each other. These bad attitudes would create social tension for the rest of the people.

...if you look at the whole scenario what worries me as I said just know, if you want to influence people in our society in a way it might create harm. Now it is (laugh) if you look at it, this is probably because I'm old.. old man, I don't like to see the situation being ripe a part or people quarrel, or unrest in our society, but what worries me is when you try influence to people in such way you might create unrest.. alright, not all change is good, but if you plan your change then probably it is good.

(P3/line1037-1045)

... as I said the fanatism, and I would say that sometime that they are actually ignorant, heart mentality, and sometime that their language

\section{Themes}

1) Be rational to accept societal development

2) Increasing public's awareness

3) Believe bad using online media can create harm

4) Online media provide space for public voice

5) Believe that education is important

6) Young generation prefer maximize the online media

7) Online media is more significant to societal development

8) Traditional media and online media are significant for societal development

9) Believe that media influence mind and thinking

Table 2: Themes of social implications. 
that they used so called very poison that it can create a social tension as well.

(P10/line2792-2795)

Definitely for those have authority, they have power, it is a trouble maker, it can create chaotic for the scenario in the country. It is out of control that is pessimistic view. Definitely some people think their position is happen so they rather maintain their status hope, and have a certain law to control it..

(P10/line3113-3117)

Furthermore, participant 10 (P10) realized that there are a group of people who create social tension by attacking at individual personally. He accused the opposition party (PKR) who did such action.

But the question here is actually now they go to attacking..so I would say the bigger group of them have the leader, I would say the Pakatan Rakyat have their good team, to create the thing, then they just spark and everyone get burning into the fire.

(P10/line3154-3158)

Moreover, participant 11 (P11) claimed that people who believed in the news posted on the online media would keep arguing and create harm in the society.

People now tend to believe more on online alternative media rather than newspaper or news in television. The implication of online media is people keep on arguing and blame each other rather than to find a solution and it can create harm.

(P11/line3446-3449)

\section{Increasing public awareness}

The other implication is the increasing level of public awareness. Publics are more alert about the social reality compared to previous years. In these circumstances, they gain various resources and realize what occur in their surroundings. For instance, the public is aware that they have their own right to voice their points of view and suggestions, even though they are in a dissident group.

People are beginning to see whether it's real or unreal what is reality in bracket.. what is reality..previously reality come only in one source.. but now the reality come in various sources, many sources..but then again you have to create your own reality.

(P3/line1465-1468)

Raising awareness of the public towards both mainstream and mediating between the political sphere and the crisis culture.

(P7/ine2041-2042)

...people get more awareness and more care this new media also contributed to social development...people participants such as government policy.

(P9/line2618-2621)

Furthermore, the awareness of public also increases the level of economy status and education as they are exposed extensively through online media. ... so means we say that we need have this kinds of news in this situation in we are living in the country have more and more educated people so we can stop thing can happen, for me this thing, simultenously increasing level of economy, level of education so its kind of something involved according to ICT.

(P9/line2546-2551)

After the public has exposed themselves through the online media, they probably could start thinking analytically about certain issues.
With a lot of information, they will search for proof or discuss with each other, and then, stand with their own principles. Generally, people would not act as blind followers, as in the previous decades, but now, they are able to debate and take action.

Yes, definitely. It is very important, because to open some people eyes,ok.. As I said maybe we start to think critically, what is happening now.

(P2/line612-614)

... my view on the that is good because we are facing... we are facing because a living in a globalization work rest a we have to be prepare, to be comment, to be criticies at the same time also the others parties also need to be prepare for the same thing.

(P9/line2466-2470)

\section{Online media provides space for public voice}

The online media allows anybody to access information and disseminate them to anyone who is ready and willing to respond. They give feedback to the opinion and commentaries in interactive and energetic manner. Such online media become a means of attainment to wider audiences regardless of time and place.

I think yes to some extent they also provide..but sometimes they try to abuse the freedom that they have.. I mean the people lah.. even the online media provide the space but it doesn't mean that you can say anything or you free to do anything, you can say anything which maybe you will punish other people image..because we have the laws and ethics...

(P2/line703-708)

I thing this medium actually has a break up some level of political mutuality, media mutuality although aaa... I must said some of the comments is what we call is inappropriate but yet a this new media actually have a provide a room for a better so call democracy.

(P9/line2472-2477)

It give people the chance to speak out regardless whether you are left or right, whether you are in the side of the fans or whether you are in that side of the fans, it allows you to speak your mind, it allows you to say things some of the things are hurtful some of the thing some of this thing are regious.. But nonetheless it alows you to say things unlike before it was difficult for you to say thing before... But now you can still...

(P3/line1100-1106)

In addition, participants three (P3) and participant nine (P9) kept reminding that Malaysians should be responsible in conveying messages through the online public sphere.

Freedom of speech yeah..again as I said.. Online allows you for that. It allows you to speak your mind. But speaking your mind without responsibility, and accountability is also negative. What we are saying is that, while the opportunity is there, make use the opportunity wisely and do it with responsibility. I think what it is.

(P3/line1564-1568)

I think that a this online news actually contribute to a some part of what we call a much more democratic situation wheres it's very rare I have to admit I believe that some a comments the also been what we call filter like Malaysiakini but generally never posted their comment it work abuse. That shows that we are the alternative media actually have contributed to what we call the mutuality of freedom of expression, freedom of speech in Malaysia.

(P9/line2459-2466) 


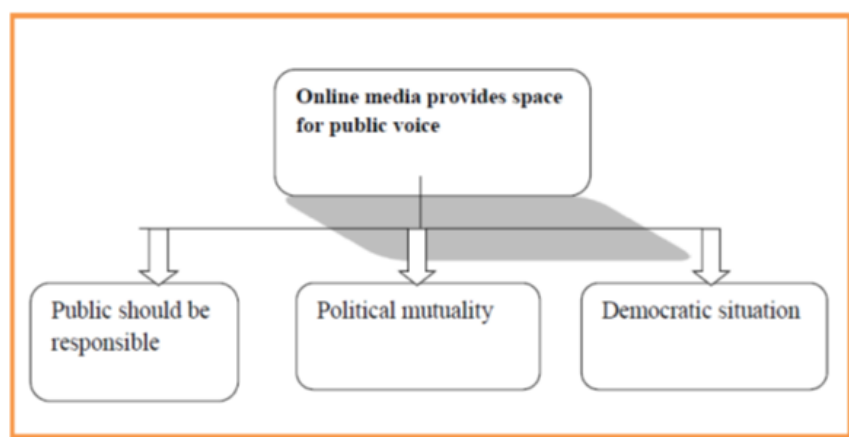

Figure 1: Online media provides space for public voice.

Based on Figure 1, the participants agreed that the online alternative media provides space for the public voice, and this situation would promote participatory democracy. Political views could not be separated in order to obtain opinion from the general public.

\section{Findings}

Among all the three news portals (Malaysiakini, Malaysia Today, and the Malaysian Insider), Malaysiakini only produces selected issues which provide brief and short statements. It follows by opinions from the readers either it is already stated in the news portal or subscribed by the readers. Obviously, this phenomenon challenges the Agenda Setting Theory.

According to Agenda Setting Theory, McCombs and Shaw concluded that the mass media exerted a significant influence on what voters considered to be the major issues. The core assumptions of this theory is it is the creation of public awareness and concern of salient issues by the news media. In the news portal, readers are actively determined what agenda or issue should be discussed while they take an action to subscribe the news from the other news agency. Agenda setting effect means the influence of the mass media created by emphasizing certain types; this would cause people to perceive the same issue that has a high impact to their social life.

However, when the degree of knowledge on literacy becomes enhanced, the arena of journalism has changed drastically. Online journalism gives a huge impact to the society because in some circumstances, people are not only waiting for the news from the news agency, but they have a lot of alternative to achieve the news from the first source.

Moreover, the public believes that the online alternative media is uniquely a medium of communication which is suited to educate, delight, inform, and persuade. The online alternative media grows in an atmosphere of freedom and responsibility or is stifled by regulation and acrimony. It depends upon the integrity, honesty, diligence, and kindness of those who use it. In regard to the issue of the online alternative media as a new medium of civic engagement, the researchers highlights the implications of reconsidering the textually of the online alternative media in addition to the spatial metaphors that are more commonly deployed to describe online alternative media activity [19]. It is to consider the online alternative media as mediated production of texts. In this analysis, the researchers can say that the online alternative media is a space for information, expression of opinions and dialogues.

Another explanation for these findings could be due to the participants' interpretations of the civility attribute, whereby a message is considered uncivil or not varied from one person to the other. This is echoed by Postmes et al. [20], who posit that people have varying perceptions of what constitutes incivility. Perhaps incivility was deemed more intolerable when participants were asked to rate the conversant as compared to rating the conversations, as they expected the conversant to exhibit greater civility towards one another [21].

The themes of participatory democracy; "develop social responsibility" considered the issues of public awareness, the public realizes the usage of bad words that could create harm in country, people need changes in their social life style, and the public begins to think critically. Dominant style by youth or so-called Y-generation, perhaps assist the tendency to lead and take control in social situation. Democracy is best served by a public sphere where competing visions of the future can be expressed and subjected to debate without skewing or censorship. Thus, civil society in this sense should be separated from the control of the state [22].

The concept of public sphere upholds another theme of participatory democracy; "build community and identity". The public sphere is thus, a crucial dimension of civil society. Civil society without a strong public sphere lacks opportunities for participation in collective choice, whether about specific policy issues or basic institutions. The public sphere is also a medium of social integration, a form of social solidarity, as well as an arena for debating possible social arrangements. People are knitted together not only by cultural similarity, but also by the opportunity to discuss issues with each other and even to consider differences.

According to Hodges and Pavela [22], the Internet is a human institution, designed to enhance the growth and development of human beings. It means that every single person using the online alternative media should be treated in ways that respects and promotes human dignity. Privacy is a component of human dignity. In addition to adhering to pertinent laws and rules, people using the online alternative media has an ethical responsibility to respect the reasonable privacy expectations of others.

The above findings prove that the mainstream mass media and online alternative media may differ in their associations with creating harm because of the component of social anxiety. The anonymity of the online alternative media may provide some protection against social anxiety experienced by those who often used bad words to create social tension. The differences in the motivations at play in the use of traditional media and online alternative media forms of communication would suggest that the two forms of communication are not functionally equivalent.

\section{Implications}

The contributions of this study could be viewed from two perspectives-theoretical and daily practices perspectives. This study was to gather concepts and data with which to suggest possible themes of participatory democracy that can be applied to the study of cultural uses of online media, networked information and communication technologies. The suggestions for a theoretical framework could be helpful for future studies of online alternative media use and implications. Perhaps the most distinguished characteristic of the Internet technologies is the accessibility, and sometimes almost simultaneous influences, of multiple encoding and decoding environments.

For online alternative media use in daily practices perspectives, mediations of texts can take place in both the local environment of use 
and in the social environments of cyberspace. Dialogue in chat rooms, discussion forums, and email can mediate interpretations of cultural texts accessed through various Internet technologies. Furthermore, simultaneous usage of Internet technologies is possible and can greatly influence the mediation of texts. For example, online conversation is becoming an increasingly common phenomenon on the Internet. Cyber-events are organized and designed for any number of purposes and often entail live participation, such as with chat rooms and discussion forums set up for Internet users to participate in the name of participatory democracy.

\section{Conclusion}

In multi-ethnic Malaysia, the effects of globalization can be felt with the emergence of alternative media providing all kinds of information; from the good to the bad, from the accurate to the inaccurate. Newfound social problems have also mushroomed, the irresponsible dissemination of rumor-mongering by bloggers and other "alternative voices". Massive information, misinformation and disinformation via the mass media are challenges for Malaysian media practitioners because they are detrimental to local values and culture [23].

Supporting such Internet development, the Communication and Multimedia Act 1998 had assured that the Internet is free from censorship. Since then, political scenario in Malaysia informally develops participatory democracy that is positive enhancing voices of the people to participate in policy and decision making of the ruling power. There are some cases such as Hindu Rights Action Force (HINDRAF), national financial crisis, and Mahathir-Anwar political crisis which show that the public have attempted to portray their views and perception of ruling leader as a result for freedom of expression [24], even though there are cases where defamation and fallacious content of the internet are significant. Nevertheless, the potential of massive increases in information, points of connectivity and the spatial scope of communication in public participation adds to the difficulty faced by many governments or regulatory bodies that want to monitor and control its content.

Lastly, with online media, it brings citizens close to government. As stated by Hale, Musso and Weare [25]; The Internet is a way to reduce the distance between the governing elite and the citizenry. A key barrier to the revitalization of democracy is that the 'experts' and 'special interests' simply have more information than the general public. This new communication medium will level the informational playing field for the average citizen. It seems logical, therefore, that the Internet could reduce the cost of communication between citizens and government (pg. 106).

However, Davis [26] quoted that "interpersonal relationships act as our moral ties to the social world. Indeed, it is our social ties that constitute our very humanness. As mediating devices, social media can connect and separate; conjoin and isolate". Simply, the implications of online media could be either positive or negative side, depends on public assessment.

\section{References}

1. Sassi $S$ (2001) The transformation of the public sphere. In: Axford B, Huggins $\mathrm{R}$ (eds.) New media and politics, Sage, London.

2. Chooi C (2011) Najib repeats promise of no Internet censorship. Malaysian Insider.

3. Kenyon AT, Marjoribanks T (2007) Transforming media market: The cases of Malaysia and Singapore. Australian Journal of emerging technologies and Society 5(2): 103-118.
4. Mujahid Y (2009) Wajah baru politik Malaysia. Anbakri Publika, Malaysia.

5. Mujibu AM, Badrul Azmier M (2012) Satu penilaian semula politik pembangunan di Malaysia In: Pemikir (ed.) Kuasa Magis BN terhakis.

6. Gong R (2011) Internet politics and state media control: Candidate weblogs in Malaysia. Communication Policy Research South, Negombo, Sri Lanka.

7. Rahman HFA, Omar N, Abidin SZZ, Mahmud Z, Rosli MM (2010) Visualizing Patterns of Online Media Preference Based on Young Adults Lifestyle: 319323.

8. Gong R (2010) Political Effects of Blogs in Malaysia: Internet politics and state media control. Candidates weblogs in Malaysia.

9. O'Leary Z (2004) The essential guide to do research. Sage, London.

10. Gill J, Johnson P (1997) Research methods for managers (2ndedn.) Paul Chapman Publishing Ltd, London.

11. Bogdan RC, Biklen SK (1992) Qualitative Research for education: An introduction to theory and methods (2ndedn.) Allyn and Bacon, America.

12. Hisham D (2008) Pragmatic approach to qualitative case study research Learning by doing: A case of distance learning research in Malaysia. Universiti Utara Malaysia Press, Sintok.

13. Othman L (2009) Penyelidikan Kualitatif: Pengenalan kepada teori dan metod. Penerbit Universiti Pendidikan Sultan Idris, Tanjung Malim.

14. Merriam SB (1998) Qualitative research and case study applications in education. Jossey-Bass Publishers, San Francisco.

15. 15. Cavana RY, Delahaye BL, Uma S (2001) Applied business research: Qualitative and quantitative methods. John Wiley and Sons, Australia.

16. 16. Noorzan MN (2010) Writing Research and thesis proposals: Guidelines and examples. University Publication Centre (UPENA), Shah Alam.

17. Creswell JW (1998) Qualitative inquiry and research design choosing among five traditions. Sage, Thousand Oaks.

18. Morse JM, Richards L (2002) Readme first for user's guide to qualitative methods. Sage, Thousand Oaks.

19. Victor LJ (2007) The fundamental reality of text.

20. Postmes T, Spears R, Lea M (2000) Breaching or building social boundaries? Side- effects of computer-mediated communication. Communication Research 25(6): 689-705.

21. Azyumardi A (2002) Islam reformis: Dinamika intelektual dan gerakan. PT RajaGrafindo Persada, Jakarta

22. Ahmad F, Chang PK, Mustaffa N, Faridah I, Wan MWA, et al. (2012) Information Propagation and the Forces of Social Media in Malaysia. Asian Social Science 8(5): 71-76.

23. Hodges MW, Pavela G (2003) Ten principles of civility.

24. Bakardjievva M (2005) Internet Society: The internet in everyday life. Sage London.

25. Hale M, Musso J, Weare C (1999) Developing digital democracy: Evidence from Californian municipal web pages. In: Barry NH, Brian DL (eds.) Digital democracy: Discourse and decision making in the information age, Routledge, London: 96-115

26. Davis JL (2012) Social Media and Experiential Ambivalence. Future Internet 4: 955-970. 